\title{
Heavy-Ion Microbeams for Biological Science: Development of System and Utilization for Biological Experiments in QST-Takasaki
}

\author{
Tomoo Funayama ${ }^{\mathbb{D}}$ \\ Department of Radiation-Applied Biology Research, Takasaki Advanced Radiation Research Institute, Quantum \\ Beam Science Research Directorate, National Institutes for Quantum and Radiological Science and Technology 1, \\ Takasaki 370-1292, Japan; funayama.tomo@qst.go.jp; Tel.: +81-27-346-9107
}

Received: 16 April 2019; Accepted: 11 June 2019; Published: 14 June 2019

\begin{abstract}
Target irradiation of biological material with a heavy-ion microbeam is a useful means to analyze the mechanisms underlying the effects of heavy-ion irradiation on cells and individuals. At QST-Takasaki, there are two heavy-ion microbeam systems, one using beam collimation and the other beam focusing. They are installed on the vertical beam lines of the azimuthally-varying-field cyclotron of the TIARA facility for analyzing heavy-ion radiation effects on biological samples. The collimating heavy-ion microbeam system is used in a wide range of biological research not only in regard to cultured cells but also small individuals, such as silkworms, nematode C. elegans, and medaka fish. The focusing microbeam system was designed and developed to perform more precise target irradiation that cannot be achieved through collimation. This review describes recent updates of the collimating heavy ion microbeam system and the research performed using it. In addition, a brief outline of the focusing microbeam system and current development status is described.
\end{abstract}

Keywords: target irradiation of biological material; High-LET radiation; heavy-ion; microbeam biology

\section{Biology and Application of Heavy-Ion Radiation}

Heavy-ion radiation is applied in heavy-ion cancer therapy [1-3] and ion-beam breeding [4-6]. These applications of heavy ions depend on its characteristic biological effects such as higher cell killings and characteristic mutagenesis. Such biological properties are considered to arise from the non-uniform distribution of microdosimetrical energy deposition of heavy ions. Nevertheless, the mechanisms underscoring the unique dose distribution of heavy ions and its specific biological effectiveness has not been sufficiently elucidated. Moreover, its non-uniformity at the cellular and cell population level prevents a detailed molecular analysis of heavy-ion radiation.

Two factors produce this microdosimetric non-uniform dose distribution. The first is a spatial distribution of energy deposition of heavy ions, called the "ion track structure" [7]. Heavy ions impinging on biological targets deposit their energy densely along their trajectories; nevertheless, just a few micrometers distant from the ion trajectory there is no energy deposition. Therefore, even if the same number of ions hit a cell, only a certain portion, for example the nucleus or cytoplasm, of the cell near the striking position will be damaged by the deposition. Furthermore, the response of the cell varies.

The second factor is the random distribution of ions hitting positions on the target sample containing a cell population. When a cell sample is irradiated with heavy ions over a broad field, providing a uniform macroscopic dose distribution, the position of each ion hit in the sample becomes random microscopically. For such broad-field irradiation, the relationship among the macroscopic 
absorbed dose $(D)$, the number of irradiated particles per area $(F)$, and the linear energy transfer $(\mathrm{LET}, L)$ is expressed as

$$
D(\mathrm{~Gy})=F\left(\mathrm{p} / \mathrm{cm}^{2}\right) \times L(\mathrm{keV} / \mu \mathrm{m}) \times 1.602 \times 10^{-9},
$$

which clearly shows that, when the number of ion hits is the same, the average absorbed dose increases as the LET rises. In contrast, when the macroscopic dose is the same, the number of irradiated particles decreases as the LET increases.

For protons, carbon ions, and argon ions, Table 1 lists the calculated values of an average dose given by a single-ion hit on cells of $100 \mu \mathrm{m}^{2}$ area, and the number of ion hits when the cells are irradiated with a macroscopic average of $5 \mathrm{~Gy}$. An ion with a high LET has a high average absorbed dose per hit. In particular, for Ar ions, a single-ion hit dose on cells is $4.4 \mathrm{~Gy}$. Therefore, a high LET ion is capable of inducing radiation responses through only single-ion hits.

Table 1. Calculated values of the macroscopic average dose given by a single ion impact on a cell and the number of ion impacts when cells are irradiated with an equal macroscopic average dose.

\begin{tabular}{ccccc}
\hline Ion Species & Energy $(\mathbf{M e V} / \mathbf{u})$ & LET $(\mathbf{k e V} / \boldsymbol{\mu m})$ & Single-Ion Hit Dose $^{\mathbf{a}}$ & Number of Ion Hits $^{\mathbf{b}}$ \\
\hline $\mathrm{H}$ & 20.0 & 2.77 & $4.4 \mathrm{mGy}$ & 1127 particles \\
$\mathrm{C}$ & 18.5 & 108 & $0.17 \mathrm{~Gy}$ & 29 particles \\
$\mathrm{Ar}$ & 11.5 & 1620 & $4.4 \mathrm{~Gy}$ & 2 particles \\
\hline
\end{tabular}

${ }^{a}$ Average absorbed dose of a single-ion hit on a cell. ${ }^{b}$ Average number of ion hits when cells were irradiated with average dose of $5 \mathrm{~Gy}$.

Another important property of heavy ions is the decrease in the number of average ion hits on a cell. The spatial distribution of ion hits is random and obeys Poisson's distribution. When the average number of hits per cell decreases and reaches a few hits, the difference in the number of ion hits for any two cells increases.

For example, in a cell sample that is irradiated with an equal number of ions, the expected ratios of cells hit by a single ion, by multiple ions, and not hit by any ion becomes $36.8 \%, 26.4 \%$, and $36.8 \%$, respectively. Therefore, it is quite difficult to figure out cellular responses of a single heavy-ion hit with an analysis of the "average single ion hit" cell sample that exhibits a cellular response of such a mixture of different ion hit states.

Any form of radiation has its elemental dose, which is defined as the amount of dose deposited in single events, such as ion hits for particle radiation, for example. Therefore, they all basically have a dose range in which such non-uniformity occurs for dose deposition on a cell population. However, for low LET radiation such as gamma-rays, there are no overlaps in the dose range of a non-uniform dose deposition and the biological effective dose range. Hence, such issues have not become obvious in conventional radiation research.

However, because a heavy ion has a high LET, which means a high elementary dose and has a biological effectiveness with a single event, biological analysis of heavy-ion radiation needs to eliminate the effect of such non-uniform dose depositions on each cell. In other words, using the absorbed dose "Gy", which is an average value of dose deposition on the whole cell population from broad-field irradiation, as an index for irradiated radiation dose is not suitable for analyzing accurately the effect of heavy-ion hits.

To estimate accurately the effect of heavy-ion radiation with high LET, it is necessary to replace the unit Gy with a new concept that reflects the number of hits, elemental dose, and ion track structure. Nevertheless, it is not well understood how elementary dose and ion track structure affect cellular responses.

In addition, such non-uniform dose distributions in a cell population induce radiation-induced bystander effects, which are induced in unhit neighboring cells by intracellular signaling from cells hit 
by radiation $[8,9]$. That is, it becomes important to clarify also the mechanism of the bystander effect when estimating radiation effects of heavy ions.

A target irradiation with heavy-ion microbeam is suitable in solving this complex issue. A beam spot of heavy-ion beam smaller than cells produced using a micro-collimator or a magnetic lens is used in the irradiation. In using a heavy-ion microbeam, it is possible to irradiate all the cells contained in the population with a uniform number of ions. Analyzing accurately the effect of single ion then becomes possible, and subsequently the mechanism of the bystander effect can be elucidated.

\section{Heavy-Ion Microbeam System of QST-Takasaki}

To solve the issues concerning the biological analysis of heavy-ion radiation effects, certain developments in heavy-ion microbeams have been conducted at the Takasaki Advanced Radiation Research Institute of National Institutes for Quantum and Radiological Science and Technology (QST-Takasaki) [10].

A microbeam that targets and irradiates a micrometer-sized area of a biological target has been used as a tool to investigate radiation effects. Several microbeams have been developed which utilize a variety of radiation from low LET to high LET [11-13]; however, due to the difficulty of microbeam spot formation, high LET microbeams have only been achieved with limited facilities such as GSI Darmstadt, Institute of Modern Physics, Chinese Academy of Sciences Lanzhou, and QST-Takasaki [10]. Almost all of these were mainly aimed at irradiating only cultured cells, however, we have developed a beam and system that can irradiate not only cells but also small model organisms by cyclotron-based heavy ion microbeams of high energy particles.

In the Takasaki Ion Accelerators for Advanced Radiation Application (TIARA) facility of QST-Takasaki, two heavy-ion microbeam systems have been installed that employ different methods to form the microbeam spot in the vertical beam lines of the azimuthally varying field (AVF) cyclotron (Figure 1). One is a collimating heavy-ion microbeam system installed at the HZ1 beam port [14]. The collimating microbeam system was planned in the late 1980s when construction of the TIARA facility began; microbeam irradiation of biological samples started in 1994. The other is a focusing heavy-ion microbeam system at the HX1 beam port that since 2005 has been developing and conducting precise cell irradiation experiments that are difficult to perform with the collimating microbeam system.

Collimating Heavy-Ion Microbeam

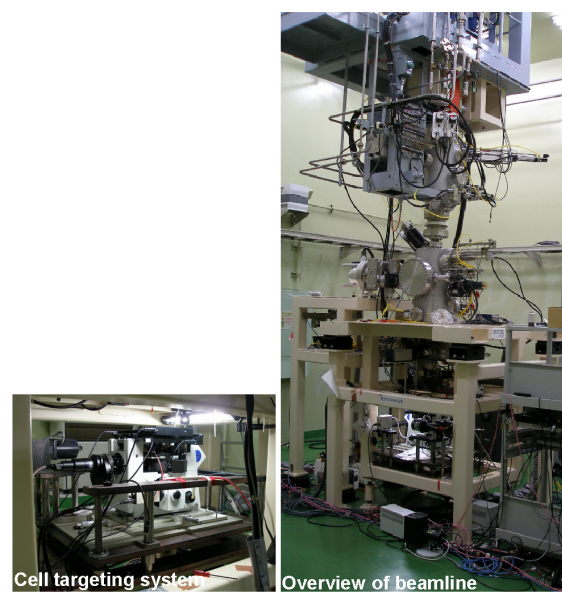

- Using microapartures for generating microbeam spot - Minimum beam size; $\sim 5 \mu \mathrm{m}$

- Wide range of ion species, beam size and LET : $\mathrm{C} \sim \mathrm{Ar}, 5 \sim 250 \mu \mathrm{m}$ in diameter, $70 \sim 1260 \mathrm{keV} / \mu \mathrm{m}$ - Utilized for biological experiment since 1994

\section{Focusing Heavy-ion Microbeam}

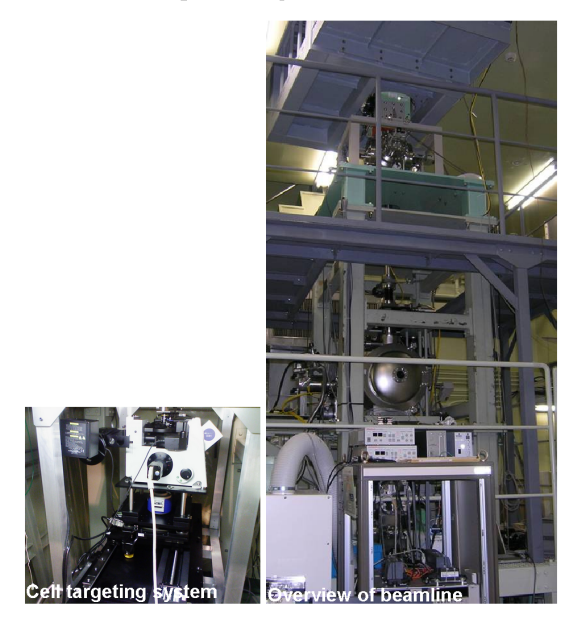

- Using magnetic lens for generating microbeam spot

- Minimum beam size; less than $1 \mu \mathrm{m}$ in vacuum

- Developed for rapid and precious targeting since 2005

Figure 1. Overview specification of heavy-ion microbeam systems of QST-Takasaki. 
This paper outlines the ongoing biological research utilizing these two microbeam systems. For the collimating heavy-ion microbeam system, an outline is already presented in a separate report [14], hence, only recent updates of the system and review of the biological research are described. In regard to the focusing microbeam system, a brief outline of the system is presented.

\section{Collimating Heavy-Ion Microbeam System}

The collimating heavy-ion microbeam system of QST-Takasaki produces a microbeam spot using a collimator with a micrometer-size pinhole. This system has been adapted to irradiate a wide range of biological targets, such as cultured cells, silkworm, Caenorhabditis elegans, medaka fish, and plant tissue. In this section, the latest specifications of the system, which are not described in the previous report, are documented. This includes the specifications of the collimator, the available beam size and ion species, recent updates of the system, and how the system has been utilized in biological experiments.

\subsection{Available Beam Size and Ion Species}

For collimation of the microbeam spot, the system uses a microaperture, which is a metal plate with a micrometer-size pinhole. The material from which the microaperture is made and the diameter of the pinhole determine the ion species available and the size of the beam spot produced. Because the system is designed to enable easy exchange of microapertures, we can select the beam size for irradiation by choosing a microaperture with a suitable pinhole diameter. The microaperture with the smallest pinhole diameter that can be used in the system is a $250 \mu \mathrm{m}$ thick tantalum plate with a $5 \mu \mathrm{m}$-diameter pinhole. With this microaperture, biological samples can be irradiated with Ne or Ar ions. There are also 5-20 $\mu \mathrm{m}$-diameter microapertures mainly for cultured cell irradiation, and $60-250 \mu \mathrm{m}$-diameter microapertures for irradiation of tissue samples and small animals. Table 2 lists the main microapertures currently used in the collimating heavy-ion microbeam system.

These microapertures are carefully selected depending on the type of sample to be irradiated and the purpose of the experiment. For experiments requiring precise irradiation of cells, we use microapertures with a pinhole diameter of $5 \mu \mathrm{m}$ to produce microbeams of Ar and Ne ions as well as with a pinhole diameter of $20 \mu \mathrm{m}$ for $\mathrm{C}$ ions. In experiments targeting and irradiating specific parts of an individual or cell population, a microaperture with a pinhole diameter corresponding to the range of the targeted region is selected. When heavy-ion microbeam irradiation is used as a radio-microsurgical tool, with which inactivation of cellular activity of a specific region of individuals is performed, the effect of irradiation on the individual varies with the extent of the region to be treated. Therefore, the wide variety of microapertures with spot sizes from $5 \mu \mathrm{m}$ to $250 \mu \mathrm{m}$ offers great advantages when employing the collimating heavy-ion microbeam system.

Table 2. Microapertures available for the collimating heavy-ion microbeam system at QST-Takasaki.

\begin{tabular}{|c|c|c|c|}
\hline $\begin{array}{c}\text { Disc } \\
\text { Material }\end{array}$ & $\begin{array}{l}\text { Pinhole } \\
\text { Diameter }\end{array}$ & $\begin{array}{l}\text { Available Ion Spieces } \\
\text { (Energy, LET) }\end{array}$ & Experimental Target \\
\hline Ta & $5 \mu \mathrm{m}$ & $\begin{array}{l}\text { - }{ }^{20} \mathrm{Ne}^{7+}(13.0 \mathrm{MeV} / \mathrm{u}, 380 \mathrm{keV} / \mu \mathrm{m}) \\
\text { - }{ }^{40} \mathrm{Ar}^{13+}(11.5 \mathrm{MeV} / \mathrm{u}, 1260 \mathrm{keV} / \mu \mathrm{m}) \\
\text { - }{ }^{40} \mathrm{Ar}^{14+}(13.0 \mathrm{MeV} / \mathrm{u}, 1130 \mathrm{keV} / \mu \mathrm{m})\end{array}$ & cultured cells \\
\hline $\begin{array}{l}\mathrm{Ta} \\
\mathrm{Au}\end{array}$ & $20 \mu \mathrm{m}$ & $\begin{array}{l}\text { In addition to the above three, the following are available } \\
\text { - }{ }^{12} \mathrm{C}^{5+}(18.3 \mathrm{MeV} / \mathrm{u}, 103 \mathrm{keV} / \mu \mathrm{m}) \\
\text { - }{ }^{20} \mathrm{Ne}^{8+}(17.5 \mathrm{MeV} / \mathrm{u}, 300 \mathrm{keV} / \mu \mathrm{m})\end{array}$ & $\begin{array}{l}\text { cultured cells } \\
\text { C. elegans }\end{array}$ \\
\hline Ta & $60 \mu \mathrm{m}$ & \multirow{5}{*}{$\begin{array}{l}\text { In addition to the above five, the following are available } \\
\text { - }{ }^{12} \mathrm{C}^{6+}(26.7 \mathrm{MeV} / \mathrm{u}, 78 \mathrm{keV} / \mu \mathrm{m})\end{array}$} & $\begin{array}{l}\text { C. elegans } \\
\text { medaka fish }\end{array}$ \\
\hline Ta & $70 \mu \mathrm{m}$ & & medaka fish \\
\hline $\mathrm{Ta}$ & $120 \mu \mathrm{m}$ & & \\
\hline $\mathrm{Ta}$ & $180 \mu \mathrm{m}$ & & medaka fish \\
\hline $\mathrm{Ta}$ & $250 \mu \mathrm{m}$ & & silkworm, A. thaliana \\
\hline
\end{tabular}




\subsection{Recent System Updates}

In past applications of this microbeam system, the biological research started with the irradiation of silkworms from the mid-1990s; the irradiation of cultured cells began in 2001 [15]. Since the detailed outline of this system given in 2008 [14], there have been a number of updates implemented, of which three major aspects are reported below.

\subsubsection{Development of a New Cell Targeting System}

The original microbeam system had initially an inverted microscope (TMD-300, Nikon, Tokyo, Japan) with customized commercial targeting software (Autoscan System Pty. Ltd., Victoria, Australia) for the cell targeting system that determined the targeting performance of the whole microbeam system. After ten years had passed since installation, parts of the system began to show ageing failures that disrupted the irradiation experiments. An automatic objective revolver of the inverted microscope was one of the failing parts. However, repairing this revolver was difficult because parts were not available. Therefore, we replaced the whole cell targeting system with a new microscope and software.

An Olympus IX81-type biological inverted microscope (Olympus, Tokyo, Japan) was adopted as the targeting microscope for the replacement system. As the IX81-type microscope can perform all of its functions under PC control without any customization, it is possible to control remotely all the microscope operations during irradiation from the preparation room. In the previous system, the automatic sample stage used a rotary encoder for determining stage position. However, its performance in stage positioning was not sufficient to target cultured cells. Therefore, we employed an automatic stage operated under closed loop control using an optical microscale encoder (BIOS-215T, Sigma Koki, Tokyo, Japan), which has a high positioning accuracy of $0.1 \mu \mathrm{m}$ or less. Moreover, the remote control method of the targeting system from the preparation room during irradiation was changed. A conventional method, which required a complicated control based on network communication, was replaced with a simpler method that extended the control PC console line to remote preparation room.

Because the hardware consisting of the cell targeting system was significantly changed, software to control the system was developed. The design was based on basic concepts used in the conventional system while being self-manufactured. By developing the software ourselves, it became possible to freely implement functions that could not be implemented using conventional commercial software. Taking this advantage, the software was implemented with a function integrating not only the control of the microscope and the automatic stage, but also beam control and ion counting, which was difficult to implement on the conventional commercial-based system. The new software became the development base for all control software for the focusing microbeam system and the offline live imaging system.

With the development of this new targeting system of the collimating microbeam system, it became possible to perform experiments on irradiation effects of heavy ions on various organisms from cells to individuals more efficiently.

\subsubsection{Utilization of New Ion Species for Microbeam Irradiation}

The AVF cyclotron of the TIARA facility can accelerate heavy ions that provide the LET of more than $1000 \mathrm{keV} / \mu \mathrm{m}$. One of the advantages of our collimating heavy-ion microbeam system is that it is able to irradiate biological samples with a microbeam of such high LET and be able to analyze their responses.

At the beginning of our cell irradiation study, the only available ion that has a LET of more than $1000 \mathrm{keV} / \mu \mathrm{m}$ was ${ }^{40} \mathrm{Ar}^{13+}(11.5 \mathrm{MeV} / \mathrm{u}$, LET $1260 \mathrm{keV} / \mu \mathrm{m}$, projectile range in water $260 \mu \mathrm{m})$. However, because of this shorter projectile range, the ion may stop in the target cell sample depending on the sample preparation conditions. The ion occasionally was not able to penetrate the sample layer and hence was not detected by the ion detector mounted beneath the sample to count and control the 
beam ions. This led to inaccuracies in the ion count on target cell and, therefore, we needed to use new ion species that had longer projectile ranges but a LET of more than $1000 \mathrm{keV} / \mu \mathrm{m}$.

With the assistance of the accelerator staff of the facility, we confirmed that ${ }^{40} \mathrm{Ar}^{14+}$ ions $(13.0 \mathrm{MeV} / \mathrm{u}$, LET $1130 \mathrm{keV} / \mu \mathrm{m}$, projectile range in water $320 \mu \mathrm{m})$ were able to be used in our collimating microbeam system. These ${ }^{40} \mathrm{Ar}^{14+}$ ions exhibit a LET of more than $1000 \mathrm{keV} / \mu \mathrm{m}$ and have a projectile range of about $60 \mu \mathrm{m}$ longer than the conventional ${ }^{40} \mathrm{Ar}^{13+}$ ions. By adopting this ion species, we were able to irradiate cells accurately regardless of preparation condition of the irradiated sample.

In addition, using cocktail beam acceleration technology, this ${ }^{40} \mathrm{Ar}^{14+}$ ion is capable of changing ion species to ${ }^{20} \mathrm{Ne}^{7+}$ ion and vice versa, within a short duration [16]. This characteristic of the ion impressed on us to change ion species and enable microbeam irradiations of different ions species within a short beam time.

\subsubsection{Update of Offline Observation System for Post Irradiation Analysis}

As supporting equipment for experiment of microbeam irradiation, a microscope, called the "offline microscope", was installed in the preparation room. This microscope has the same specification as the online microscope installed on the beam line for target irradiation. It is used in registering the coordinates of the targeted cell for automatic irradiation, and to observe cellular responses of individual hit cells by revisiting the cells using the positional database. However, to elucidate the effect of ion hits on a cell population, not only is it indispensable to analyze individually the responses of the cells with ion hits, but non-hit bystander cells need also to be analyzed for a long duration after irradiation.

Therefore, we updated the offline microscope system and built an imaging system that supports long-term live imaging of the bystander effect. Two necessary devices were introduced to the system. One is an automatic focusing unit that eliminates focus drift during long-term imaging observations. The other is a high-sensitivity sCMOS camera (ORCA-Flash4.0, Hamamatsu Photonics, Hamamatsu, Japan) that is able to detect weak fluorescence of cells using attenuated excitation light to minimize cell damage. This camera has a comparable sensitivity of an EM-CCD camera; moreover, it has a higher resolution and wider field of view. The software for long-term live imaging was developed based on the cell targeting software of the collimating microbeam system. By developing the updated system, performing long-term whole-population imaging of the bystander effect induced by microbeam irradiation is now possible.

\subsection{Experimental Protocols for Biological Applications}

For more than 20 years, the collimating heavy-ion microbeam system has been used for local irradiation of a wide variety of biological targets. They included not only cultured cells such as normal human fibroblasts, immune cells, and lung cancer cells but also samples derived from tissues such as myofibrillar cells isolated from mouse muscle tissue, and individuals such as eggs and larvae of silkworms, Caenorhabditis elegans, Arabidopsis thaliana, and embryos and adults of the medaka fish. The protocols used for irradiating these samples fall into roughly three classes: manual targeting irradiation, target irradiation using a predefined positional database, and programmed matrix irradiation, which does not target specific cells (Figure 2). These three irradiation methods and the results of life science research performed using them are explained below. 
Manual Targeting Irradiation

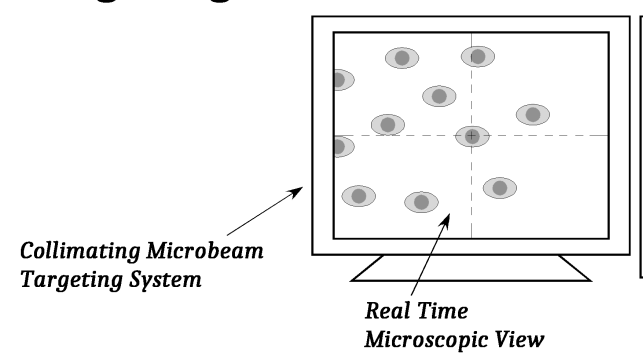

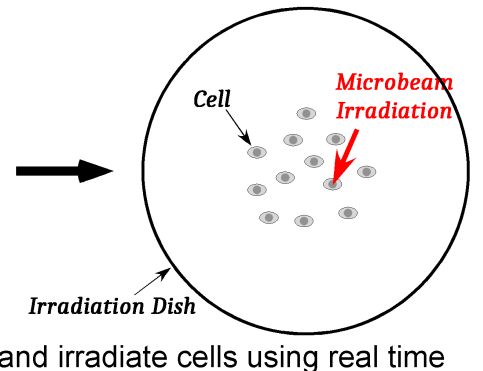

Target and irradiate cells using real time microscopic view

Target Irradiation with Predefined Positional Database

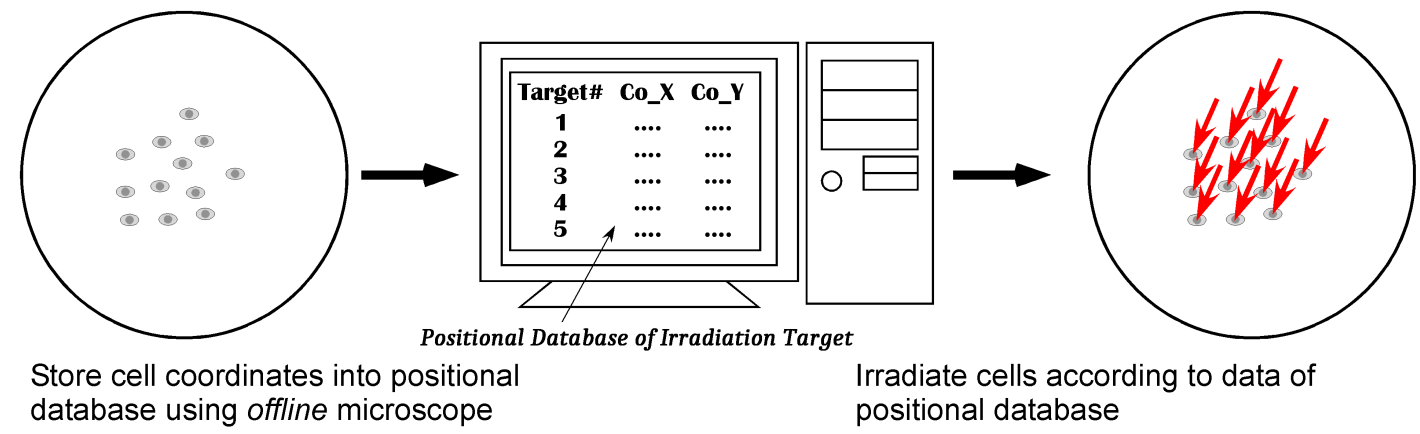

\section{Programmed Matrix Irradiation without Targeting Specific Cells}
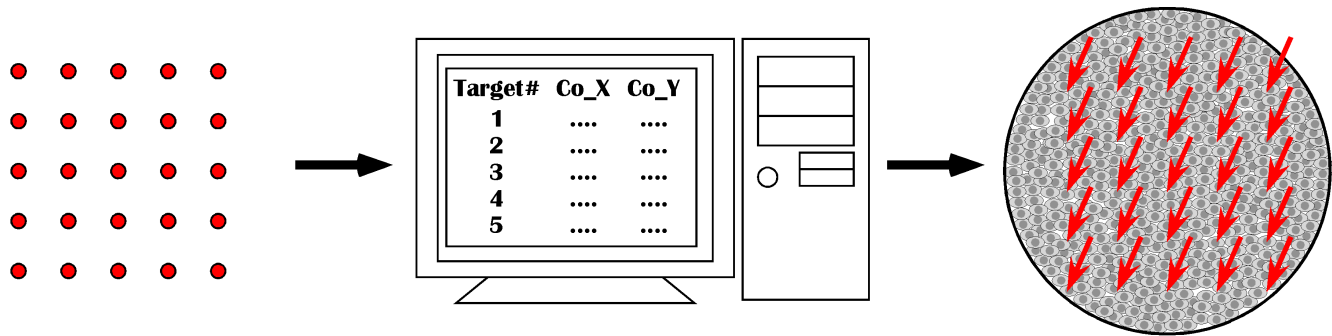

Define irradiation coordinates and store into positional database

Irradiate confluent cells according to programmed coordinates

Figure 2. Schematic diagram of irradiation protocols for microbeam irradiation using collimating system.

\subsubsection{Manual Targeting Irradiation}

Manual targeting irradiation is a protocol in which the points or areas of the sample to be irradiated are manually targeted one by one with the online microscope installed on the beam line and immediately irradiated with a defined number of heavy ions. The advantage of this protocol is that it can be applied to all kind of samples that can be observed with the online microscope. The disadvantage is that, for each irradiation point, the operation takes more than a minute because the protocol asks for the selected targeting points one at a time. Hence, in practice, irradiating a large number of cells in a cell irradiation dish is difficult. However, this drawback does not become a problem when the targeted region in the sample is one of a few points. For this reason, a manual targeting protocol has been mainly used in experiments that locally irradiate a specific region of individuals and examine its response after irradiation.

One of the early studies using this protocol was a study that determined a fate map of the silkworm. Blastoderm stage eggs of the silkworm, Bombyx mori, were placed on a transparent plastic film $100 \mu \mathrm{m}$ thick and manually one by one a specific spot of $250 \mu \mathrm{m}$ diameter was irradiated with 
a carbon ion microbeam to inactivate the embryonic nuclei. Thereafter, the morphological abnormality after development were scored in a correlation with the irradiated region to determine a fate map of the egg [17]. Adopting almost the same method, the relationship between irradiation and somatic mutations in diapause-terminated eggs was examined. Specific spots on the eggs were targeted and irradiated with a carbon ion microbeam, and thereafter somatic mutations in the 5th instar larva were examined. The irradiation of the embryonic part of the eggs induced somatic mutations appearing as white spots in the developed larvae. However, irradiation of the yolk did not, indicating that there are no non-targeted bystander effects during the radiation-induced somatic mutagenesis of silkworm eggs [18].

The manual irradiation protocol was also used in examining the mechanisms of hydrotropism of the Arabidopsis thaliana root. Root caps and elongation zones of the root tissue were manually targeted and irradiated with a carbon ion microbeam of diameter $180 \mu \mathrm{m}$, to explore their role in root hydrotropism. The results of the irradiation experiments indicated that both tissues have distinct but indispensable function in this phenomenon, but, for de novo gene expression for hydrotropism, the elongation zone plays a more important role [19].

To irradiate the sample with a microbeam, the target needs to remain stationary. Unlike silkworm eggs and plants tissue, small animal targets that can potentially move around must be fixed in a specific place in the sample dish for irradiation. Therefore, we have been developing methods to restrain these animals.

In an irradiation study of 1st instar larvae of silkworms-knobbed epidermal mutants that form protuberances (knobs) after the third molting — a method for holding a silkworm larva was established. For that purpose, aluminum plates with holes matching the size of the larvae were developed to confine them during irradiation. They were then covered with Mylar film to prevent them from moving out of the hole. The most notable knobs form in the fifth larval segment of the 5th instar larvae. Hence, these segments of the 1st instar larvae were irradiated with a carbon-ion microbeam, and thereafter the formation of knobs was observed. The irradiation suppressed the formation of knobs in their development, indicating knobs were formed by the excessive proliferation of the epidermis [20,21].

Nematodes (C. elegans) are always active, and therefore restricting their movement also becomes an important issue in irradiation studies. In targeting gonad cells of $C$. elegans and analyzing the effect of irradiation on targeted cells and their neighboring cells, we chose to anesthetize individuals to suppress their movement and irradiate them manually [22].

However, using anesthetics on nematodes is difficult when analyzing irradiation effects concerning learning and locomotion because anesthetic prevents measuring the responses immediately after irradiation. To solve this issue, a novel experimental method to immobilize the worms without an anesthetic during targeted irradiation was established enabling the immediate response from local irradiation on the nervous system to be analyzed. The worms were placed in a straight, microfluidic channel in a polydimethylsiloxane (PDMS) chip, and covered with a plastic coverslip to enclose them and inhibit their free motion. Thereafter, the worms were targeted under microscopy and irradiated with a heavy-ion microbeam. This chip was ion-penetrable ultra-thin, and wettable to avoid the worms drying up. We identified a suitable buffer solution to maintain good worm conditions in the channel. Using this method, irradiating a specific region of $C$. elegans with the exact number of heavy ions is now possible as well as analyzing the immediate response on locomotive activity [23-25].

In other local irradiation experiments on individuals, target irradiation of the embryonic midbrain of medaka fish, Oryzias latipes, was also performed. Embryos at the 30-somite stage were placed in an irradiation dish and covered with an $8 \mu \mathrm{m}$-thick polyimide film to maintain embryonic body direction and hold surrounding water. Thereafter, the optic tectum region of embryonic brain was targeted and irradiated with a $250 \mu \mathrm{m}$-diameter carbon-ion microbeam. Activation of the microglia was observed only in the irradiated area in a $24 \mathrm{~h}$ period after irradiation, however, it had spread over the whole brain in three days after irradiation. This result indicates that localized irradiation of the brain induces abscopal and persistent activation of microglia [26]. 
As described above, we have used mainly the manual targeting protocol in experiments in irradiating local regions of individuals. We will continue with this protocol to perform experiments using individuals, and we intend to advance the analysis of individual radiation responses.

\subsubsection{Target Irradiation with Predefined Positional Database}

Target irradiation with predefined positional database is an irradiation protocol that reduces the duration of irradiation using a positional database of cell positions. The coordinates of cells in an irradiation dish were registered in advance by the offline microscope placed in the preparation room, which has the same specifications as the online microscope. The irradiation of cells was continuously performed on the online microscope following the coordinates stored in the database. This protocol is a method optimized in targeting irradiation on individual cells accurately, and adopted in experiments in analyzing heavy-ion hit effects on cultured cells.

Our first cell irradiation experiment using heavy-ion microbeams was performed using this protocol. Chinese hamster-derived cultured cells CHO-K1 were targeted and irradiated with an Ar ion microbeam. The result revealed that a single hit with an Ar ion on a cell nucleus almost completely suppresses their proliferation [15]. Target irradiation of the protoplast of the cultured cell of the tobacco BY-2 strain was also examined using this protocol. BY-2 protoplasts were irradiated with a $20 \mu \mathrm{m}$-diameter carbon ion microbeam, and, thereafter, the colony formation rate was measured [27]. Moreover, the effect of a heavy-ion hit on mouse skeletal muscle was also examined using this protocol. Target positions of isolated muscle fiber cells placed on an irradiation dish were preregistered by the offline microscope, and then irradiated with carbon ion microbeam. After irradiation, the changes in cell membrane and intracellular structure by the ion hit were observed in electron microscopy [28-30].

\subsubsection{Programmed Matrix Irradiation without Targeting Specific Cells}

The preregistered positional database shortens the irradiation time by registering the coordinates of target cells; however, it does not lead to a significant shortening of the total experimental time, which includes time required for registering coordinates using the offline microscope. This means that, even if the irradiation process becomes faster using positional database, the total throughput of a cell irradiation experiment is limited. In contrast, the methods of analysis used in exploring the mechanisms of the radiation-induced bystander effect, such as the measurement of micronuclei formation and mutation frequency, molecular biological assay of bystander-related genes and proteins, requires obtaining many cells that induce the bystander effect within a shorter experimental time. A programmed matrix irradiation protocol was established to fulfill such requirements for this bystander effect study.

In programmed matrix irradiation protocol, the target cells are confluently cultured on the bottom of the irradiation dish. Microbeam irradiation of the cells is performed using positional database of the programmed matrix coordinates without targeting specific cells. Because the bottom of the dish is completely covered with cells, irradiated ions are assured to hit some cells. When the programmed targeted point is much less than the number of cells contained in the dish, the sample contains a very small number of irradiated cells and a vast number of unhit bystander cells. In this mixture of irradiated and non-irradiated cells, the response of hit cells is difficult to observe in a biological assay, and the result of the assay almost shows the response of the unhit bystander cells.

The first experiment using this protocol examined a micronucleus formation in cultured normal human fibroblast. Normal human fibroblast AG01522 cells were cultured confluently on the bottom of the irradiation dish, then the cells were irradiated with an $\mathrm{Ar}$ or $\mathrm{Ne}$ ion microbeam. A maximum of $121(11 \times 11)$ sites of the programmed matrix was used for targeting, and one ion was irradiated per site. The time required for irradiation including sample exchange was less than $10 \mathrm{~min}$ per sample, so that by using this protocol we were able to complete irradiation using the microbeam in a short time as for broad field irradiation. After four hours of post irradiation cultivation, we examined the frequency of micronucleus formation. Although only up to 121 cells out of $7 \times 10^{5}$ cells were 
irradiated, the frequency of micronucleus formation of irradiated sample increased approximately 1.4 times, indicating that the irradiation of very limited number of cells induces a bystander increase in micronucleus formation in unhit neighboring cells [31-33]. The result of this study confirmed that this protocol is quite useful in the analysis of the bystander effect. Encouraged by this confirmation, we began conducting many bystander studies using this protocol.

Bystander studies using normal human fibroblasts were performed with the focus of attention on various endpoints, such as cell survival rate, frequency of micronucleus formation, phosphorylation of histone $\mathrm{H} 2 \mathrm{AX}$, apoptosis, and induction of p53 protein [34-39]. Moreover, gene expression analysis of bystander cells using the DNA microarray assay revealed that the G protein/PI-3 kinase pathways were activated in the bystander cells but not in directly irradiated cells [40].

Programmed matrix irradiation was adopted also to analyze the bystander effect of human immune cells. Monocites of human immune cell line THP-1 were differentiated to macrophages, and, thereafter, a $0.45 \%$ fraction of the cell population was irradiated with a carbon ion microbeam. Assays of cytokine production after irradiation revealed that the production of TNF- $\alpha$ and IL- 6 were suppressed by the bystander effect [41].

Furthermore, the bystander effect in confluent cells and cells in exponential growth phase were compared using two different protocols. Confluent human cancer cell line A549 cells were irradiated with the programmed matrix; a fraction of the cells in exponential growth phase were irradiated based on the preregistered positional database. The result of a colony formation assay indicated that the cell survival of confluent cells diminished but not of exponential growth cells, indicating the bystander effect was induced in the former but not the latter. Therefore, an intercellular signaling via gap junction is presumed to be involved in the induction of the bystander effect in human lung cancer [42].

\section{Focusing Heavy-Ion Microbeam System}

Using the collimating heavy-ion microbeam system, much biological research was performed with a variety of biological targets. To advance this research, a more precise targeting irradiation with a smaller beam spot was necessary. However, there is a limitation to beam spot size because of technical limitations regarding the method of beam formation.

One technical limitation is the difficulty in manufacturing a small size pinhole in a thick metal disk. To produce a smaller beam spot, a smaller pinhole collimator is required. Moreover, the thickness of the metal disk in which the pinhole is drilled cannot be thinner to make pinhole fabrication easier because its thickness is determined by the ion projectile range in a metal disk. Another limitation is beam scattering at the edge of the pinhole. As collimator pinhole size decreases, the fraction of scattered ions increases. Therefore, even if the smaller pinhole collimator is possible, creating a smaller beam spot by beam collimation remains difficult because the ions that are scattered outside the beam spot of a non-scattered ion enlarges the whole beam spot size.

Therefore, we designed and installed a new focusing heavy-ion microbeam system that enables the formation of precise beam spots in another vertical beam line, the HX1 line, of the AVF cyclotron, and have developed a method for performing precise irradiation of biological targets.

\subsection{System Outline}

The focusing heavy-ion microbeam system generates a beam spot using a magnetic lens. The details of the beam optics have already reported elsewhere [43-45] and it is therefore only described in brief. The heavy-ion beam from the AVF cyclotron was introduced into the HX1 vertical beam line with a ninety degrees bending magnet. After extracting this beam with object slits, the beam was focused with a quadruplet quadrupole magnet. The minimum diameter achieved for the microbeam spot was $1 \mu \mathrm{m}$ in vacuum. For performing high-speed single ion irradiation on micrometer-sized targets, a beam scanner that enables beam scanning of the targets was installed.

To irradiate specific regions of individual cells with this fine microbeam spot, a cell targeting system was installed under vacuum windows that extracted microbeam in air. The system consists of 
a fully-automated inverted microscope (IX81, Olympus, Tokyo, Japan) and multiple automatic stages (Sigma Koki, Tokyo, Japan). Software to control the system was developed based on the cell-targeting system software for the collimating microbeam system.

\subsection{Irradiation of Cells with Focusing Heavy-Ion Microbeam}

Using this focusing microbeam, we performed preliminary cell irradiation experiments. Images of the cells stained with vital staining fluorescent dye were taken with a high sensitivity camera, and the positions of the cells were extracted using image analysis from the obtained images. Thereafter, the cells were irradiated by moving the automatic stage in accordance with the preregistered cell coordinates or by scanning with the beam spot using a beam scanner. After irradiation, we confirmed heavy-ion hits on targeted cells by immunostaining using marker phosphorylated histone H2AX. Currently, we are improving the irradiation method to enable responses of individual cells hit by single heavy ions to be analyzed.

\section{Conclusions-Biological Sciences Using Heavy-Ion Microbeam}

Heavy-ion microbeams at QST-Takasaki have been generated to elucidate the biological effects of heavy ions by breaking down the non-uniformity of the dose deposition of heavy ions. However, while developing the various irradiation methods and their utilization in research, it become apparent that the method involving localized heavy-ion irradiation of biological targets is useful not only in the limited area of radiobiological research but across various branches of scientific research including neurobiology, physiology, zoology, systems biology, and space life science. In the future, we look further to developing this extremely useful heavy-ion microbeam irradiation technology and apply it not only to radiobiological research but also to biological science research in general.

Funding: This work was supported in part by JSPS KAKENHI Grant Nos. 16710039, 20612013, 24310073, 16K00552, and 18H04991 to T.F.

Acknowledgments: I thank the staff of the TIARA facility, collaborators using our heavy-ion microbeam system, and members of Project "Microbeam Radiation Biology" including past members, for their kind support in the research introduced in this report. I thank Richard Haase, Ph.D for editing a draft of this manuscript.

Conflicts of Interest: The author declares no conflict of interest.

\section{Abbreviations}

The following abbreviations are used in this manuscript:

$\begin{array}{ll}\text { LET } & \text { Linear Energy Transfer } \\ \text { QST } & \text { National Institutes for Quantum and Radiological Science and Technology } \\ \text { AVF } & \text { azimuthally varying field } \\ \text { TIARA } & \text { Takasaki Ion Accelerators for Advanced Radiation Application } \\ \text { sCMOS } & \text { scientific Complementary Metal-Oxide-Semiconductor } \\ \text { EM-CCD } & \text { Electron Multiplying Charge Coupled Device } \\ \text { PDMS } & \text { polydimethylsiloxane }\end{array}$

\section{References}

1. Tsujii, H.; Mizoe, J.; Kamada, T.; Baba, M.; Tsuji, H.; Kato, H.; Kato, S.; Yamada, S.; Yasuda, S.; Ohno, T.; et al. Clinical results of carbon ion radiotherapy at NIRS. J. Radiat. Res. 2007, 48 (Suppl. A), A1-A13. [CrossRef] [PubMed]

2. Tsujii, H.; Mizoe, J.E.; Kamada, T.; Baba, M.; Kato, S.; Kato, H.; Tsuji, H.; Yamada, S.; Yasuda, S.; Ohno, T.; et al. Overview of clinical experiences on carbon ion radiotherapy at NIRS. Radiother. Oncol. 2004, 73, S41-S49. [CrossRef]

3. Amaldi, U.; Kraft, G. European developments in radiotherapy with beams of large radiobiological effectiveness. J. Radiat. Res. 2007, 48 (Suppl. A), A27-A41. [CrossRef] [PubMed] 
4. Yamaguchi, H.; Nagatomi, S.; Morishita, T.; Degi, K.; Tanaka, A.; Shikazono, N.; Hase, Y. Mutation induced with ion beam irradiation in rose. Nucl. Instrum. Methods Phys. Res. Sect. B 2003, 206, 561-564. [CrossRef]

5. Mei, M.; Deng, H.; Lu, Y.; Zhuang, C.; Liu, Z.; Qiu, Q.; Qiu, Y.; Yang, T.C. Mutagenic effects of heavy ion radiation in plants. Adv. Space Res. 1994, 14, 363-372. [CrossRef]

6. Tanaka, A.; Tano, S.; Chantes, T.; Yokota, Y.; Shikazono, N.; Watanabe, H. A new Arabidopsis mutant induced by ion beams affects flavonoid synthesis with spotted pigmentation in testa. Genes Genet. Syst. 1997, 72, 141-148. [CrossRef] [PubMed]

7. Chatterjee, A.; Schaefer, H.J. Microdosimetric structure of heavy ion tracks in tissue. Radiat. Environ. Biophys. 1976, 13, 215-227. [CrossRef]

8. Hamada, N.; Matsumoto, H.; Hara, T.; Kobayashi, Y. Intercellular and Intracellular Signaling Pathways Mediating Ionizing Radiation-Induced Bystander Effects. J. Radiat. Res. 2007, 48, 87-95. [CrossRef]

9. Matsumoto, H.; Hamada, N.; Takahashi, A.; Kobayashi, Y.; Ohnishi, T. Vanguards of Paradigm Shift in Radiation Biology: Radiation-Induced Adaptive and Bystander Responses. J. Radiat. Res. 2007, 48, 97-106. [CrossRef]

10. Kurashima, S.; Satoh, T.; Saitoh, Y.; Yokota, W. Irradiation facilities of the Takasaki Advanced Radiation Research Institute. Quantum Beam Sci. 2017, 1, 2. [CrossRef]

11. Gerardi, S. Ionizing Radiation Microbeam Facilities for Radiobiological Studies in Europe. J. Radiat. Res. 2009, 50, A13-A20. [CrossRef]

12. Bigelow, A.; Garty, G.; Funayama, T.; Randers-Pehrson, G.; Brenner, D.; Geard, C. Expanding the Question-answering Potential of Single-cell Microbeams at RARAF, USA. J. Radiat. Res. 2009, 50, A21-A28. [CrossRef] [PubMed]

13. Kobayashi, Y.; Funayama, T.; Hamada, N.; Sakashita, T.; Konishi, T.; Imaseki, H.; Yasuda, K.; Hatashita, M.; Takagi, K.; Hatori, S.; et al. Microbeam Irradiation Facilities for Radiobiology in Japan and China. J. Radiat. Res. 2009, 50, A29-A47. [CrossRef] [PubMed]

14. Funayama, T.; Wada, S.; Yokota, Y.; Fukamoto, K.; Sakashita, T.; Taguchi, M.; Kakizaki, T.; Hamada, N.; Suzuki, M.; Furusawa, Y.; et al. Heavy-ion microbeam system in JAEA for microbeam biology. J. Radiat. Res. 2008, 49, 71-82. [CrossRef] [PubMed]

15. Funayama, T.; Wada, S.; Kobayashi, Y.; Watanabe, H. Irradiation of mammalian cultured cells with collimated heavy ion microbeam. Radiat. Res. 2005, 163, 241-246. [CrossRef] [PubMed]

16. Kurashima, S.; Ichi Yoshida, K.; Oikawa, M.; Satoh, T.; Miyawaki, N.; Yuyama, T.; Okumura, S.; Kashiwagi, H.; Ishibori, I.; Nara, T.; et al. Quick change of ion species of heavy-ion microbeam by cocktail beam acceleration technique with the JAEA AVF cyclotron. Nucl. Instrum. Methods Phys. Res. Sect. B 2009, 267, 2024-2027. [CrossRef]

17. Kiguchi, K.; Shirai, K.; Kanekatsu, R.; Kobayashi, Y.; Tu, Z.; Funayama, T.; Watanabe, H. Radiosurgery using heavy ion microbeams for biological study: Fate mapping of the cellular blastoderm-stage egg of the silkworm, Bombyx mori. Nucl. Instrum. Methods Phys. Res. Sect. B 2003, 210, 312-315. [CrossRef]

18. Furusawa, T.; Fukamoto, K.; Sakashita, T.; Suzuki, E.; Kakizaki, T.; Hamada, N.; Funayama, T.; Suzuki, H.; Ishioka, N.; Wada, S.; et al. Targeted heavy-ion microbeam irradiation of the embryo but not yolk in the diapause-terminated egg of the silkworm, Bombyx mori, induces the somatic mutation. J. Radiat. Res. 2009, 50, 371-375. [CrossRef]

19. Miyazawa, Y.; Sakashita, T.; Funayama, T.; Hamada, N.; Negishi, H.; Kobayashi, A.; Kaneyasu, T.; Ooba, A.; Morohashi, K.; Kakizaki, T.; et al. Effects of locally targeted heavy-ion and laser microbeam on root hydrotropism in Arabidopsis thaliana. J. Radiat. Res. 2008, 49, 373-379. [CrossRef]

20. Fukamoto, K.; Shirai, K.; Sakata, T.; Sakashita, T.; Funayama, T.; Hamada, N.; Wada, S.; Kakizaki, T.; Shimura, S.; Kobayashi, Y.; et al. Development of the irradiation method for the first instar silkworm larvae using locally targeted heavy-ion microbeam. J. Radiat. Res. 2007, 48, 247-253. [CrossRef]

21. Fukamoto, K.; Shimura, S.; Shirai, K.; Kanekatsu, R.; Kiguchi, K.; Sakashita, T.; Funayama, T.; Kobayashi, Y. Effects of heavy-ion irradiadion on the differentiation of epidermal cells in the silkworm, Bombyx mori. J. Insect Biotechnol. Sericol. 2006, 75, 107-114. [CrossRef]

22. Sugimoto, T.; Dazai, K.; Sakashita, T.; Funayama, T.; Wada, S.; Hamada, N.; Kakizaki, T.; Kobayashi, Y.; Higashitani, A. Cell cycle arrest and apoptosis in Caenorhabditis elegans germline cells following heavy-ion microbeam irradiation. Int. J. Radiat. Biol. 2006, 82, 31-38. [CrossRef] [PubMed] 
23. Suzuki, M.; Hattori, Y.; Sakashita, T.; Yokota, Y.; Kobayashi, Y.; Funayama, T. Region-specific irradiation system with heavy-ion microbeam for active individuals of Caenorhabditis elegans. J. Radiat. Res. 2017, 58, 881-886. [CrossRef] [PubMed]

24. Suzuki, M.; Sakashita, T.; Hattori, Y.; Yokota, Y.; Kobayashi, Y.; Funayama, T. Development of ultra-thin chips for immobilization of Caenorhabditis elegans in microfluidic channels during irradiation and selection of buffer solution to prevent dehydration. J. Neurosci. Methods 2018, 306, 32-37. [CrossRef] [PubMed]

25. Suzuki, M.; Sakashita, T.; Funayama, T. Immobilization of live Caenorhabditis elegans individuals using an ultra-thin polydimethylsiloxane microfluidic chip with water retention. JoVE 2019, e59008. [CrossRef] [PubMed]

26. Yasuda, T.; Kamahori, M.; Nagata, K.; Watanabe-Asaka, T.; Suzuki, M.; Funayama, T.; Mitani, H.; Oda, S. Abscopal activation of microglia in embryonic fish brain following targeted irradiation with heavy-ion microbeam. Int. J. Mol. Sci. 2017, 18, 1428. [CrossRef] [PubMed]

27. Yokota, Y.; Funayama, T.; Kobayashi, Y.; Sakashita, T.; Wada, S.; Hase, Y.; Shikazono, N.; Tanaka, A.; Inoue, M. Development of an ion microbeam system for irradiating single plant cell[s]. Biol. Sci. Space 2003, 17, 298-301. [CrossRef]

28. Hino, M.; Wada, S.; Tajika, Y.; Morimura, Y.; Hamada, N.; Funayama, T.; Sakashita, T.; Kakizaki, T.; Kobayashi, Y.; Yorifuji, H. Heavy ion microbeam irradiation induces ultrastructural changes in isolated single fibers of skeletal muscle. Cell Struct. Funct. 2007, 32, 51-56. [CrossRef]

29. Hino, M.; Hamada, N.; Tajika, Y.; Funayama, T.; Morimura, Y.; Sakashita, T.; Yokota, Y.; Fukamoto, K.; Kobayashi, Y.; Yorifuji, H. Insufficient membrane fusion in dysferlin-deficient muscle fibers after heavy-ion irradiation. Cell Struct. Funct. 2009, 34, 11-15. [CrossRef]

30. Hino, M.; Hamada, N.; Tajika, Y.; Funayama, T.; Morimura, Y.; Sakashita, T.; Yokota, Y.; Fukamoto, K.; Mutou, Y.; Kobayashi, Y.; et al. Heavy ion irradiation induces autophagy in irradiated C2C12 myoblasts and their bystander cells. J. Electron Microsc. 2010, 59, 495-501. [CrossRef]

31. Shao, C.; Furusawa, Y.; Kobayashi, Y.; Funayama, T.; Wada, S. Bystander effect induced by counted high-LET particles in confluent human fibroblasts: A mechanistic study. FASEB J. 2003, 17, 1422-1427. [CrossRef] [PubMed]

32. Shao, C.; Furusawa, Y.; Kobayashi, Y.; Funayama, T. Involvement of gap junctional intercellular communication in the bystander effect induced by broad-beam or microbeam heavy ions. Nucl. Instrum. Methods Phys. Res. Sect. B 2006, 251, 629-638. [CrossRef]

33. Matsumoto, Y.; Hamada, N.; Aoki-Nakano, M.; Funayama, T.; Sakashita, T.; Wada, S.; Kakizaki, T.; Kobayashi, Y.; Furusawa, Y. Dependence of the bystander effect for micronucleus formation on dose of heavy-ion radiation in normal human fibroblasts. Radiat. Prot. Dosim. 2015, 166, 152-156. [CrossRef] [PubMed]

34. Hamada, N.; Hara, T.; Omura-Minamisawa, M.; Ni, M.; Funayama, T.; Sakashita, T.; Sora, S.; Nakano, T.; Kobayashi, Y. Heavy-ion microbeam irradiation induces bystander killing of human cells. Biol. Sci. Space 2008, 22, 46-53. [CrossRef]

35. Hamada, N.; Ni, M.; Funayama, T.; Sakashita, T.; Kobayashi, Y. Temporally distinct response of irradiated normal human fibroblasts and their bystander cells to energetic heavy ions. Mutat. Res. 2008, 639, 35-44. [CrossRef] [PubMed]

36. Autsavapromporn, N.; Suzuki, M.; Funayama, T.; Usami, N.; Plante, I.; Yokota, Y.; Mutou, Y.; Ikeda, H.; Kobayashi, K.; Kobayashi, Y.; et al. Gap junction communication and the propagation of bystander effects induced by microbeam irradiation in human fibroblast cultures: The impact of radiation quality. Radiat. Res. 2013, 180, 367-375. [CrossRef]

37. Autsavapromporn, N.; Plante, I.; Liu, C.; Konishi, T.; Usami, N.; Funayama, T.; Azzam, E.I.; Murakami, T.; Suzuki, M. Genetic changes in progeny of bystander human fibroblasts after microbeam irradiation with X-rays, protons or carbon ions: The relevance to cancer risk. Int. J. Radiat. Biol. 2015, 91, 62-70. [CrossRef]

38. Tomita, M.; Matsumoto, H.; Funayama, T.; Yokota, Y.; Otsuka, K.; Maeda, M.; Kobayashi, Y. Nitric oxide-mediated bystander signal transduction induced by heavy-ion microbeam irradiation. Life Sci. Space TRes. 2015, 6, 36-43. [CrossRef]

39. Fournier, C.; Barberet, P.; Pouthier, T.; Ritter, S.; Fischer, B.; Voss, K.O.; Funayama, T.; Hamada, N.; Kobayashi, Y.; Taucher-Scholz, G. No evidence for DNA and early cytogenetic damage in bystander cells following heavy ion micro-irradiation at two facilities. Radiat. Res. 2009, 171, 530-540. [CrossRef] 
40. Iwakawa, M.; Hamada, N.; Imadome, K.; Funayama, T.; Sakashita, T.; Kobayashi, Y.; Imai, T. Expression profiles are differentiated in carbon ion-irradiated normal human fibroblasts and their bystander cells. Mutat. Res. 2008, 642, 57-67. [CrossRef]

41. Mutou-Yoshihara, Y.; Funayama, T.; Yokota, Y.; Kobayashi, Y. Involvement of bystander effect in suppression of the cytokine production induced by heavy-ion broad beams. Int. J. Radiat. Biol. 2012, 88, 258-266. [CrossRef] [PubMed]

42. Harada, K.; Nonaka, T.; Hamada, N.; Sakurai, H.; Hasegawa, M.; Funayama, T.; Kakizaki, T.; Kobayashi, Y.; Nakano, T. Heavy-ion induced bystander killing of human lung cancer cells: The role of gap junctional intercellular communication. Cancer Sci. 2009, 100, 684-688. [CrossRef] [PubMed]

43. Oikawa, M.; Kamiya, T.; Fukuda, M.; Okumura, S.; Inoue, H.; Masuno, S.; Umemiya, S.; Oshiyama, Y.; Taira, Y. Design of a focusing high-energy heavy ion microbeam system at the JAERI AVF cyclotron. Nucl. Instrum. Methods Phys. Res. Sect. B 2003, 210, 54-58. [CrossRef]

44. Oikawa, M.; Satoh, T.; Sakai, T.; Miyawaki, N.; Kashiwagi, H.; Kurashima, S.; Okumura, S.; Fukuda, M.; Yokota, W.; Kamiya, T. Focusing high-energy heavy ion microbeam system at the JAEA AVF cyclotron. Nucl. Instrum. Methods Phys. Res. Sect. B 2007, 260, 85-90. [CrossRef]

45. Oikawa, M.; Satoh, T.; Kamiya, T.; Kurashima, S.; Okumura, S.; Miyawaki, N.; Kashiwagi, H.; Fukuda, M.; Sakai, T.; Yokota, W. Characteristics of focusing high-energy heavy ion microbeam system at the JAEA AVF cyclotron. Appl. Radiat. Isot. 2009, 67, 484-487. [CrossRef] [PubMed]

(C) 2019 by the author. Licensee MDPI, Basel, Switzerland. This article is an open access article distributed under the terms and conditions of the Creative Commons Attribution (CC BY) license (http://creativecommons.org/licenses/by/4.0/). 